\title{
Is the Breadth of Individualized Ranges of Optimal Anxiety (IZOF) Equal for all Athletes? A Graphical Method for Establishing IZOF
}

\author{
Diana Pons, Isabel Balaguer, and M. Luisa Garcia-Merita \\ University of Valencia
}

\begin{abstract}
Recall and direct methods to determine the individual zone of optimal funtioning (IZOF) cannot account for potential individual differences in the span of optimal anxiety. Accordingly, an attempt was made to test a graphical technique that could establish the span of optimal anxiety ranges for individuals. State anxiety (STAI; Spielberger. Gorusch, \& Lushene. 1970; and CSAI-2; Martens, Burton, Vealey, Bump, \& Smith, 1990) was assessed before competitions ( 10 to 20 ) in six Spanish golfers during a season. Pelformance in each match was determined using golf scores and self-fatings. Optimal anxiety ranges were established graphically by plotting individual scores of precompetition anxiety agatnst individual performance values. Optimal ranges were also determined using Hanin's (1986, 1989) direct and recall methods. The efficacy of each method was contrasted by comparing performance between cases in which the golfers possessed oplimal of non-optimal anxiety according to each method. More of the golfers performed better when competing within an IZOF established with the graphic procedures than witl the other methods. Key words: outstanding performance, individual zone of optimal functioning
\end{abstract}

Los métodos directo y retrospectivo para establecer la zona individual de óptimo funcionamiento (IZOF) no consideran las posibles diferencias individuales en la amplitud del rango de ansiedad óptima. Por este motivo se sometió a prueba un método gráfico que permitiera establecer la amplitud de los rangos de ansiedad óptima de forma individualizada. La ansiedad estado (STAl; Spielberger, Gorusch y Lushene, 1970; y CSAI-2; Martens, Burton, Vealey, Bump y Smith, 1990) se evaluó antes de las competiciones $(10$ a 20) en seis jugadores de golf a lo largo de una temporada. EJ rendimiento de cada competición se estableció utilizando el número de golpes efectuados y autointormes. Los rangos de ansiedad optima se establecieron gráficamente, representando los niveles de ansiedad precompetitiva frente a los rendimientos de cada jugador. También se establecieron los rangos de ansiedad óptima, empleando los métodos directo y retrospectivo propuestos por Hanin (1986, 1989). La eficacia de cada método fue contrastada comparando el rendimiento de los casos en los que el nivel de ansjedad se situaba dentro o fuera de la zona establecida de óptimo funcionamiento. Comparando los tres métodos, la mayoría de los jugadores de golf rindieron mejor cuando competian dentro de su IZOF establecido con el procedimiento gráfico.

Palabras clave: rendimiento sobresaliente, zona individual de óptimo funcionamiento

The Conselleria de Cultura, Educación y Ciència of the Generalitat Valenciana supported this study.

Correspondence concerning this article should be addressed to Dr. Diana Pons, Departamento de Personalidad, Evaluación y Tratamientos Psicológicos. Facultad de Psicología. Universidad de Valencia. Av. Blasco lbañez, 21. 46010 Valencia (Spain).

E-mail: Diana.Pons@uves 
The relationship beaween anxicty and sport performance is one of the classical issues in the field of sport psyclology. Despite considerable study, support for the traditional explanations of this relationship, such as the inverted-U hypothesis is lacking (Landers \& Boutcher, 1986: Martens, Vealey, \& Burton, 1990; Raglin, 1992). One of the primary explanations for the failure of these traditional theories is that they do not account for individual differences in the way anxiety has been found to infucnce the performance of athletes. A number of reviews of this literalture have favored Hanin's (1986, 1989, 1994a) individual zones' of optinal fanctioning (IZOF) model as a useful allernative in studying the anxiety-performanee ralationship, becaluse it explicitly incorporates the notion that althletes respond dilferently to anxiety (Gould \& Krane, 1992).

The IZOF model contends that each athlete possesses an optimal zone or range of anxiety that is most beneficial for performance (Hanin, 1978, 1986, 1994a). This optimal anxicty level an vary considerably and may range from very low to very high, depending on the individual athlete. Also, this variation should exist for athletes in any given sport and should not be affected by the athlete's skill or experience. Research also supports the notion that performance is significantly better when competing athletes have anxiety levels withint their ow optinal zone (Gould, Tulfey, Hardy, \& Loachbaum, 1993; Krane, 1993; Raglin \& Turner. 1993; Tumer \& Raglin, 1996; Woodman, Albison, \& Hardy, 1997).

Hanin (1986, 1989) has described wo methods by which an athlete's optimal anxiety zone may be determined. In the direct method, anxicty is assessed prior to a series of performances unti] an outstanding or personal best performance occurs, Initial research by Hanin (1978, 1989). using the Russian version of the SIAI (Spielberger. Gorusch. \& Lushene, 1970), indicated that by adding and subtracting 4 anxiety units (approximately one-half standard deviation) to/from this anxiely score, the optimal zone of anxiety was obtained. So, for instance, if an athlete has an anxicty score in the STAI of 40 before setting a personal record performance, then that athlete's optimal zone would range from 36 to 44 . Because this method is time and resource consuming. and may be impossible in some citcumstances, Hanin (1986, 1989) developed an altemative method based upon recall. In this case, athletes fill in the STAI with instructions to respond to each of the items according to how they recallod feeling right before their best porformance. As with the direct method, four anxiety STAI units are added and subtracted from this total to yield the optimal zone. Hanin recommended that a recall method should be uscd as a bisic technique to establish the individualized optimal zones based on an athlete's past performance history. Research by Hanin $(1978,1989)$ and others supports the utility of recall method (Turner \& Raglin, 1996). Significant correlations ranging between .60 and .80 have been found between recalled and actual past precompetition anxiety values, and performance tended to be better when precompetition anxiety fell within the IZOF derived from recalled values (Raglin \& Turner, [993: Turner \& Raglin, 1996).

Although there is empirical support for the recall method, and despite the fact that this retrospective approach has been adopted in other anxiety theories Jones. Hanton, \& Swain, 1994), several limitations are evident. First, reseatch has lound that some althletes are inaccurate in recalling past anxiety (Rialin \& Morris, 1994). Secoldd, there is evidence that the accuracy of recall is higher for more recent events (Harger \& Raglin, 1994). and some studies have found that recall accuracy may drop to unacceptably low levels at spans as short as seven months (Imlay, Carda, Stanbrough, Dreiling, \& O'Connor, 1995). Third, even in cases in which the correlation beween recalled and real past precompetition anxiely is high, considerahle variance remains unalcounted for, and this could lead to errors in establishing the [ZOF. Foutth, in some cases, the result of the competition has been hypothesized to bias the Ievel of recalled anxiety (Brewer, Van Raalte, Linder, \& Van Ratilc, 1991).

In addition to these concerns, Hanin (1994a) proposed that not onty does the icvel of optimal anxicty vary considerably across atbletes, but also, so should the effective breadth of this zone of optimal functioning vary. Conceptually, this is consistent with the initial IZOF" nodel and should cnhance its usefulness. Unforturtately, each of the elassic methods used employ a standardized optimai anxiety range (i.c. optimal \pm 4 anxiety units) and do not include ways to modify the range of the optimal functioning for individual athetes.

As a consequence of these issues, in the current study, an effort was made to develop and test a graphical method for establishing individualized ranges of optimal anxiety, and to delermine if this range varies in the sample. Direct assessments of precompetition anxicty were made prior to a series of perlormances. Because somc researchers (Gould, luffey, Hardy \& Loachbaum, 1993) have proposed that spott-specific anxicty measures. sucl as the Competitive State Anxjety Inventory-2 (CSAl-2; Martens, Burton. Vealey, Bump, \& Smith, 1990). would enhance the effectiveness of IZOF, both the STAI (Spielberger, Gorusch \& Lushene, 1970) and the CSAI-2 (Martens, Burton, Vealey, Bump. \& Smith, 1990) were used. And, because research (Raglin, Morgan, \& Wisc, 1900) has found subjective measures of performance to be more useful than objective measures in testing the effectiveness of the 17OF, both subjective and objective performance criteria were included. The graphic method was then contrasted with optimal anxiety zones established using Hanin's (1986, 1989) direct and recall techniques to compare their relative usefulness.

\section{Method}

\section{Participants}

Young golfers rather than adults were chosen in order to facilitate comparison with the athlete sample from the 
published IZOF rescarch on the ability to recall past precompetition anxiety (Raglin \& Morgan, 1988; Raglin, et al., 1990; Raglin \& Turner. 1992; Raglin \& Turner, 1993). Junior-level golfers from a local club who were at the advanced level (handicup below 8) were invited to take part in this study. These who agreed to participate signed an informed consent before taking part in the investigation. The final group was limited 10 gollers who had filled in the anxicty scales al 10 or more competitions (10 to 20 competitions) and who had al least one outstanding (i.e., personal best or equal to his or her personal best) performance in those competitions. The final group consisted of six golfers, two females and four males, ranging in age from 16-20 ycars old with a mean age of 17.1. The golters had been involved in sports for an average of 7.1 ycars, and had played competitively for 6.1 years. Their average handicap was $3.9(S D=3$, range $=0.4$ to 8$)$.

\section{Instruments}

Spanish versions of the following questionnaires were employed in this investigation.

Stale-Trail Anxiety Inventory (STAI; Spielberger, Gorusch, \& Lushene, 1970). Only the state subscale was used. In the adaptation of the STAI to Spanish, the scoring differs from the English version. Both versions consist of 20 Likett-type items, but in the Spanish version, the scoring on each item ranges from $0-3$ rather than $1-4$. The items are also totaled differently. In the Spanish version, the 10 positively worded items (anxiety absent) are subtracted from the total score of the 10 negatively worded items (anxiety present), alsd a constant of 30 is added. Total scores range from a minimum of 0 to the maximum anxicty of 60 (this change affects the mean but not the psychometric properties of the scale). The age group mean for the Spanish version of the SIAI is 22.8 $(S D=10.8)$. The alpha coefficient ranged from 8610.92

Comperitive Stale Anxicty liventory-2 (CSAI-2; Martens, Burton, Vealey. Bump, \& Smith, 1990). The cognitive and somatic subscales of the Spanish version (Roca, Pérez $y$ Láaro, 1991; Pons, 1994) of the CSAl-2 were used in this study. In this version. the cognitive scale has only 8 items because the first item of the English version was not directly translatable, and so, was climinated. Hence, scores in this seale range from 8 to 32 rather than from 9 to 36 . The Spanish somatic subscale, like the original version, has 9 items. Responses of each item are scored in a Likert-type scale, ranging from 1 (not at all) to 4 (very much so). Therefore, total scores on the somatic subscale range from 9 to 36. Martens et al. (1990) reported the means and standard deviation of the CSAI-2 subscales in various sports. In golf, the sample was made up of 113 players and the results were: CSAI-2 cognitive $M=16.97, S D=5.45$ and CSAI-2 somatic $M=15.31, S D=3.91$. In our study, the CSAI-2 cognitive and somatic subscales obtained means of
$M=18.45(S D=5)$ and $M=[3.31(S D=2.5)$, respectively. Reliability coefficients for the CSAI-2 ranged from .79 to .81 on the cognitive subscale and from .82 10 .83 on the somatic subscale (Martens et al., 1990).

\section{Procedure}

At the beginning of the season, the investigators met with each golfer to reacquaint them with the procedure and to record personal data about participation in golf. At this time, the participants filled in the STAI and the CSAI-2, with the instructions to answer the items according to "how you remember fecling before your best competition," in order to establish optimal anxiety scores based on recall Incthod as proposed by Hanin (1986, [989).

One hour before each competition during the season, participants again filled in the STAI and the CSAI-2. responding to each of the items according to "how you feel at the present moment." Following each competition, we collected both objective performance measures (number of strokes to complete the 18 holes minus the individual's landicap), and subjective ones (satisfaction with his or her performance at this competition on a 0 to 10 scale, where 0 was very. very matisfied and 10 was very very satisfied).

\section{Determination of the Optimal Zone}

Three methods were used to establish optimal anxiety for each subject. Separate optimal zones were determined for the STAI and CSAI-2, as well as for objective and subjective perfomance criteria. In accordance with Hanin's (1986, 1989) suggestions for the recall method, recalled best-performance-anxiety values, as measured with the STAI and the CSAJ-2, were used to identify optimal anxicty. In the direct method, the best match for each golfer was first identified. This was done separately using both objective (number of strokes) and subjective (satisfaction) criteria. The precompetition anxiety score for that best match was defined as the optimal value. In the event of ties (two cases), the mean of the optimal anxiety values was determined. 'J'o establish the optimal zone for the STAI, four anxiety units (i.e., one-hall standard deviation) were added to and subtracted from the optimal value, resulting in a optimal range of 9 units. This procedure was repeated for the CSAI2 subscales, and the optimal range based on one-half standard deviation of these scales was established. In our sample, the range of the optimal zone was 7 units for cognitive scale, and 5 units for somatic scale.

In the direct method of establishing optimal anxiety, anxiety is typically assessed before competitions until a personal best performance results. In the present case, optimal anxicty was cstablished using the best performance out of all avaliable cases where anxiety data had been collected. Technically, this differs from the direct method used by Hanin $(1986,1989)$, but all the golfers rated this 


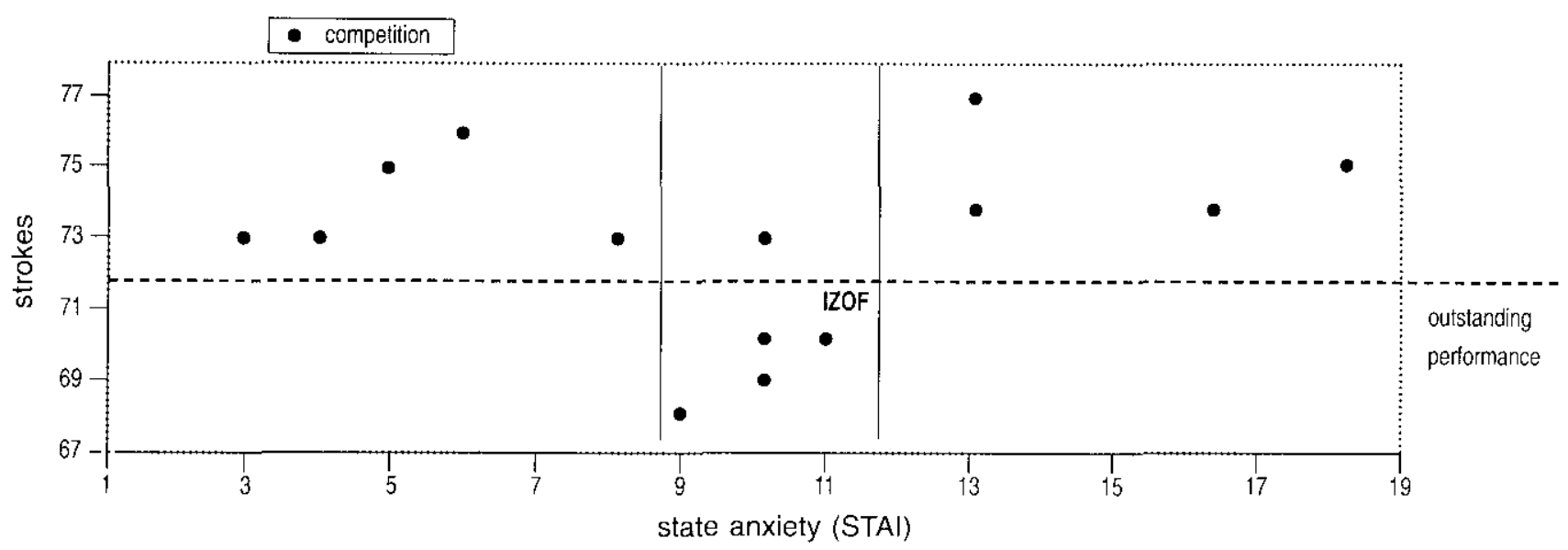

Figure 1. Relationship between state anxiely (STAl) and objective performance (strokes = score minus handicap) and IZOF for subject 3 .

performance as outstanding, and in several instances it represented a personal best performance.

Because the procedures developed by Hanin (1986, 1989) for establishing optimal anxiety employ a standardized optimal range of anxiety (i.e., optimal \pm 4 units) despite the possibility that the span of optimal ranges also differs across athletes, a graphical method that could yield individualized optimal anxiety ranges for each subject was developed. This graphical method was essentially a variant of the direct method. For each individual golfer, precompetition anxiety scores were plotted against performance scores as shown in Figures 1 and 2. Separate plots were made for the objective and subjective performance criteria. A criterion measure of outstanding performance was established a priori. For the objective measure, performances were considered outstanding when the total score of the golfer (strokes made to complete the 18 holes minus the handicap) was below par for the course (i.e., 72). For the subjective criteria, matches with ratings equal to or above a score of 8 on the 10-point performance-rating scale were judged as outstanding (one standard deviation above the mean of satisfaction, considering the values obtained in our sample: $M=5.0$ and $S D=3.1$ ).

The optimal range for the golfer was then determined by cxamining the plot and identifying all performances that fell within the outstanding category. The lower and upper boundaries of the optimal zone were established based on the highest and lowest anxicty values in the outstanding calegory. Figure 1 shows that all of the optimal anxiety values were closely clustered within a narrow zone. However, in two cases, for each of the anxiety questionnaires, one outlier was evident (sce Figure 2). In these cases where the clustering was less obvious and following the classical procedure, the upper and lower boundaries of the optimal zonc were limited to those anxiety values that fell within one half a standard deviation of the mean anxicty value of all optimal scores for that individual.

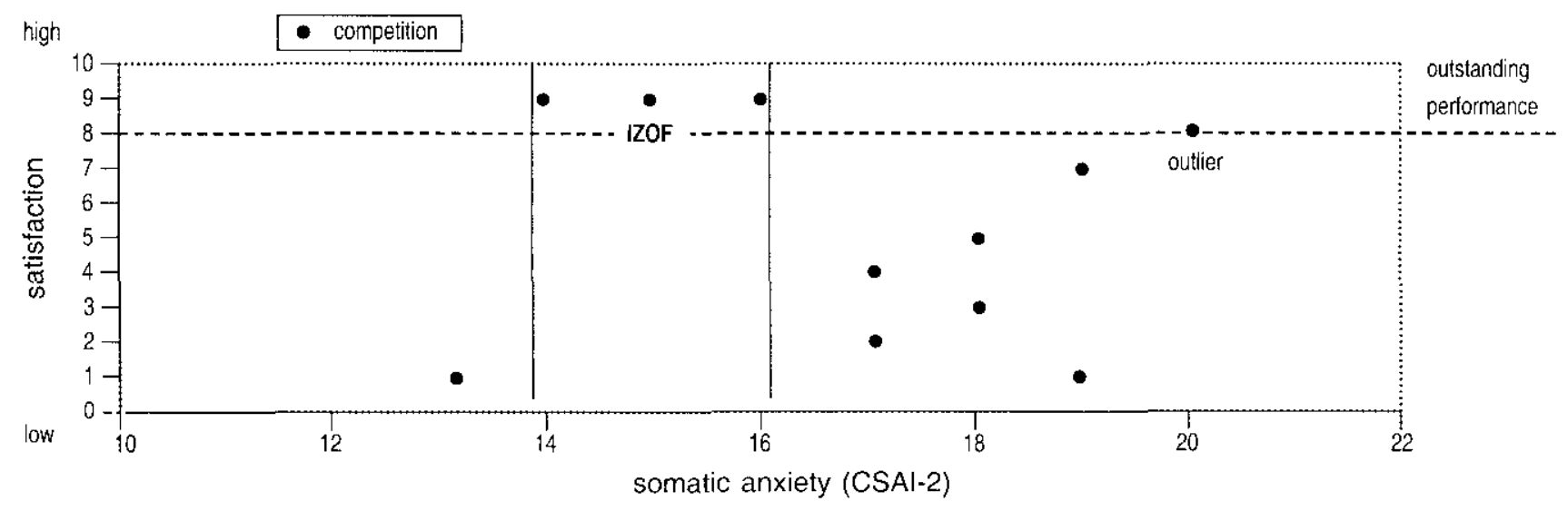

Figure 2. Relationship between somatic anxiety (CSAI-2) and subjective performance (satisfaction) and IZOF for subject 5. 


\section{Statistical Analyses}

Differences between mean performance scores were compared in cases in which the anxiety values were inside or outside (i.e., ubove or below) the optimal range for each method via one-way ANOVAs for each golfer. Comparison was conducled for each performance criterion and separately for the STAI, and the CSAI-2 subscales. The relative efficacy of the methods for determining optimal anxiety was compared by establishing the percentage of competitions that were correctly identified as outstanding or less-thanoutstanding on the basis of the optimal anxiety ranges (i.e., number of outstanding performances inside the zone, added to less-than-outstanding performances outside the zone). The variability in the span of the optimal anxiety ranges formed using the graphic method was determined and the similarity of the optimal anxiety ranges of the three methods was determined by cstablishing the percentage of times the ranges overlapped.

For example, as can be scen in Figure 2, the IZOF range for somatic anxiety determined by the graphic method for participant 5 was 14 to 16 . According to the direct method, because there was a tie between 14,15 , and 16, we cmployed the value of 15 (the averagc) as the optimum anxiety score and IZOF fell between 13 and $17(15 \pm 2)$. Participant's recalled optimum somatic anxicty value was 17 ; therefore, according to the recall method, IZOF was between 15 and $19(17 \pm 2)$. Once the IZOF boundaries had been calculated by each method, a one-way ANOVA was carricd out (for each of the methods) to check the differences in subjective performance (satisfaction) as a function of whether his somatic anxiety was within, above, or below his IZOF. The percentages of correctly classified competitions were calculated, as already explained.

Results

\section{Performance inside and outside IZOF}

One-way ANOVAs were generated singly for cach participant's performances to determine whether performances inside and outside the optimal zone differed significantly. Table 1 summarizes these findings and indicates the number of subjects whose performance was statistically better $(p \leq .05)$ for each method of establishing IZOF. Similar results were found for subjective and objective criteria and for each anxiety scale. The optimal anxiety zone established with the graphic method resulted in the largest number of golfers whose performance was statistically better $(p \leq .05)$ inside the zoncs than outside. The direct method resulted in the next highest number of good performances, and the recall method resulted in the fewest significantly better cases.

\section{Percentages of correct classifications}

As a means of determining the relative efficacy of the three methods for establishing optimal anxiety, the percentage of correcl predictions of either outstanding or less-thanoutstanding performances, based on precompetition anxiety, was determined and contrasted across methods. This was done by determining the percentage of all "outstanding" (i.e., scores at or below par, taking into account the participant's handicap, self-rating of satisfaction of 8 or higher) that fell inside the optimal zone established by each method. Similarly, the total percentage of less-thanoutstanding performances that fell outside (i.e., above or below) each zone was determined. These two values were then averaged to yield a single value that indicated the overall mean accuracy of the method based on the percent of correct predictions.

Table 2 shows the percentages of correct predictions for each scale and performance criterion. For both subjective and objective criteria, the graphic method resulted in the highest number of correct predictions, mean percentage was 73.7 (range: $67.8 \%$ to $82.6 \%$ ). The direct method resulted in a mean of $64.1 \%$ correct predictions (range: $57.5 \%$ to $70.9 \%$, and the recall method resulted in a mean of $51.1 \%$ (from $40.7 \%$ to $64.2 \%$ ). Moreover with the STAI and taking into account the objective performance, it is possible to determine the most effective IZOF $(82.6 \%)$, followed by the CSAI-2 somatic (77.0\%), and lastly the CSAI-2 cognitive $(69.3 \%)$.

Table 1

Number of Subjects out of the Total Sample $(N=6)$ whose Mean Performance Values were Significantly $(p<.05)$ Better Inside the Optimal Anxiety Zone

\begin{tabular}{lcccccc}
\hline \multirow{2}{*}{ Scale } & \multicolumn{3}{c}{ Objective Performance } & \multicolumn{2}{c}{ Subjective Performance } \\
\cline { 2 - 6 } & recall & direct & graphic & recall & direct & graphic \\
\hline STAI & 1 & 3 & 4 & 2 & 3 & 4 \\
CSAI-2 cog & 0 & 1 & 3 & 0 & 1 & 2 \\
CSAI-2 som & 1 & 1 & 3 & 1 & 2 & 3 \\
\hline
\end{tabular}

Note. CSAI-2 cog = cognitive subscale; CSAI-2 som = somatic subscale. 
Table 2

Average Corfey Classification (in Percentage) of Outstanding Pafonnances Inside WOF and Less-dhan-Outstanding Porfonnances

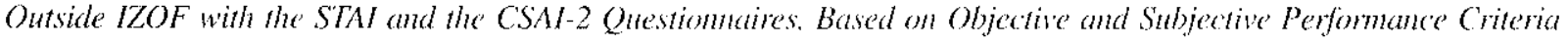

\begin{tabular}{|c|c|c|c|c|c|c|}
\hline \multirow{2}{*}{ Scale } & \multicolumn{3}{|c|}{ Objective Perlormance Crileria } & \multicolumn{3}{|c|}{ Subjective Performance Criteria } \\
\hline & Recall & Dited & Graphic: & Reciall & Dircet & Graphic \\
\hline STAI & 43.0 & 70.9 & 82.6 & 53.8 & 64.3 & 75.0 \\
\hline $\operatorname{CSAI}-2 \operatorname{cog}$ & 40.7 & 57.5 & 69.3 & 43.5 & 58.6 & 67.8 \\
\hline CSAI-2 som & 61.5 & 70.0 & 77.0 & $6.4,2$ & 0.3 .1 & 70.7 \\
\hline
\end{tabular}

Note. CSAI-2-Cog = cognitive subscale; $\operatorname{CSA}[-2-\operatorname{som}=$ somalic subscale.

\section{Comparison of optimal ranges by method}

If optimal anxiety, established directly or by recall, nearly always fell within the graphical $120 \mathrm{~F}$. then additional value of the graphic method would be negligib]e. Its benefit would also be limited if the optimal tange for the graphical method were similar to the 9-unit range for the STAI used with the other methods. However, considerable interindividual differences in the optimal ringe established hy the graphic method were found, with the optimal range spanning from 2 to 10 units across subjects. For all the subjects, the mean optimal range was $M=3.8(S D=2,22)$ in the $S T A I, M=$ $4.8(S D=3.06)$ in the CSAI-cognitive, and $M=3.16(S D$ $=1.16)$ in the CSAI-somatic.

There was also a considerable degree of discrepancy in the optimal anxiety values as established by the three methods. The optimal STAl anxiety value, based on recall. fell within optimal range based on the direct method in $33 \%$ of the cases $(2 / 6)$, and $17 \%(1 / 6)$ of the cases based on the graphical method. For the CSAI-2 cognitive, recalled anxiety before a best performance fel] within the optimal ratnge based on the direct method in $50 \%$ of the cases (3/6), and in $66 \%(4 / 6)$ of the cases using the graphical optimal rallge. For the CSAI-2 somatic scale, recalled anxiety helore a best performance fell within optimat range based on the direet method in $66 \%$ of the cases (4/6), and also in $66 \%(4 / 6)$ of the cases based on the graphic optimal range. Considering the minimum and maximtm score of the subscale, the variability was higher for the CSAI-2 cognitive, followed by the STAI and finally the CSAl-2-somatic (see Table 3).

Examination of the six participants' IZOF, using cither the STAI or the CSAl-2, indicates that there were overlaps between the uppes and lower ranges of the boundaries of the IZOF range. Nol only dict the optimal span of anxiety differ considerably across subjects, but also the anxiety values of the span (see Table 3). When the raw scores were converted to standard scores (perentiles), we found that the lowest and highest observed score of the optimal zones in the STAI corresponded to the standard scores of 5 and 70 (according to the intespretation noms for the Spanish sample); for the CSAI-2 cognitive scale. the standard scores ranged from 30 to 92, and from 2 10 68 for the CSAI-2 somatic scale (in both cases, according to the norms proposed by Matens et al. in 1990, cmploying a sample of American golf players).

\section{Discussion}

A graphical method for determining the zone of optimal anxiety in young golfers was developed and tested in this study. Optimal anxiety zones established by this method for the STAI and CSAI-2 were then contrasted with zones crealed using the recall and direct procedures described by Hanin (1986, 1989). Optintal ranges were established using both subjective and objective criteria in ofder to examine the relative uselulness of these means of measuring perfomance.

Table 3

Observed Range (Raw Scores) of the Lower and Upper Bondaries for the Graphic Zone of Optimal Functioning

\begin{tabular}{|c|c|c|}
\hline $\begin{array}{l}\text { Anxiety Measures } \\
\text { (Score range) }\end{array}$ & $\begin{array}{c}\text { Range of Scores or the Lowest } \\
\text { L7OF Measure }\end{array}$ & $\begin{array}{c}\text { Range of Scores of lac Highest } \\
\text { IZOF Mcasure }\end{array}$ \\
\hline STAI $(0-60)$ & $7-25$ & $10-28$ \\
\hline CSAI-2-cog $(8-32)$ & $12-20$ & $15-27$ \\
\hline CSAI-2-som $(9-36)$ & 4.14 & $11-17$ \\
\hline
\end{tabular}

Notr. CS-I-2-cog = cognitive subscale: CSAI-2-som = somatic subscale. 
Compcting within an optimal anxiety zone, no matter by which method it was established, was associated with the tendency to perform better. However, we found that gollers were more likely to have outstanding performances when their precompetition anxiety values were within the optimal range as determined by the graphic method, compared with either the recall or th direct method. This trend held in each of the anxiety measures and in both perfomance criteria, despite some differences in the optimal zone ranges eslablished using objective and subjective performance criteria.

The graphic method was found to be the most effective in distinguishing outstanding from less-than-outstanding periormances, followed by the direct method, and then the recall method. It should be noted, however, that one would expect the graphical method to result in more cases of outstanding performance when anxiety was within the optimal zone because the optimal anxiety range was established, ipso facto based on calses of outstanding performance, with the exception of outlicrs. An important follow-up study would be to test the relative efficacy of this and other methods for subsequent performances of these golfers, in onder to determine whether the optimal range, as defined by the graphic method, would hold for future performances. More sophisticated analyses were not carricd out because of the small number of participants in the group and the generalization problems involved. Therefore, replications with larger samples and different sports are needed.

Some dissimilarity was found across the three methods for determining optimal anxicty zoncs. As might be anticipated, the greatest discrepancy occurred with the recall method. Recalled optimal anxicty values fell within the optimal zone estahlished using direct or graphic method in only $56 \%$ of all cases, (9/16 for both). Some lack of consistency was also found between the direct and graphic methods. Yet, each of these methods resulted in correct predictions of performance (i.e., better than good when within the zone, less than good when outside the zonc), which exceeded chance, with a trend toward greater accuracy with the graphic method. Optimal anxiety ranges established using the graphic method were found to vary considerably among athletes. For example, the range of the graphic optimal zone was 2 to 10 for the STAI, with a mean range of 3.8 units. This range is less than half of that created using the recall and direct methods (i.c., 9 units), suggesting thit the graphic method is a way to accurately establish the optimal anxiety range for individual athlotes. This is consistent with the latest developments of the IZOF model made by Hanin (1994a, 1994b), such as the Compulerized Adapted Assessment Program. It is noteworthy that the traditional optimal anxiety range of nine units encompasses nearly all the optimal ranges based on the sraphic method. indicating that the traditional range should work well for groups of athletes whose optinal anxiety spans cannot be otherwise determined. However, it is equally clear that the range differs dastically in this sample of athletes, and when individual optimal anxiety spans are used, the eflicacy of the 1ZOF method is enhanced.

Optimal anxiety, as assessed with either the STAI or the CSAI-2 subscales, was found to be associated with better performances, with a small difference in favor of the STAI. However, consistent differences favoring one scale over another were observed for some gollers. In some cases, optimal anxicty as determined with the STAI was more closely related to optimal performance, whereas for other golfers, one or both of the CSAI-2 scales were better. This lack of a consistent advantage of CSAI-2 over the STAI does not support the widely held view that sport specific psychological measures are more useful than general measures (Gould et al., 1993, Jones et al., 1994). The findings are consistent with Hanin's (1994a) concepualization of the IZOF model, which posits that the relevance of items from anxiety scales will differ from one athlete to another. The relcvance of anxiety as a factor influencing performance also differed from one athlete to another. In some cases, it is clear that a good performance commonly occurred no matler what the golfer's' anxicty level was. This suggests that. for some athletes, anxiety, no matter how it is assessed, has little effect on performance. It is also possible that other emotional states may be important for optimal performance. Hanin (1994a, 1994b) has developed methods for determining which emotions are most crucial for individual athletes and at which level of intensity.

Summing up, the present findings indicate that a graphic mothod for determining $\mathrm{l} Z \mathrm{OF}$ is golfers results in optimal anxiety ranges that differ from the recall and direct methods described by Hanin $(1986,1989)$. Not only did the optimal anxiety span vary considerably among the golfers, but the results also suggest that the graphic fechnique provides an additional refinement to the other methods of determining IZOF. because it provides a way to establish the effective anxicty range for each athlete.

\section{References}

Brewer. B.W., Van Raalte. J.L., Linder, D.E. \& Van Railte, N.S. (1991). Peak performance and the perils of retrospective introspction. Jownal of Spont \& Etercion Psycholog, 8, 227238.

Grould, D., \& Krane, V. (1992). The arousal-athletic pertormance relationship: Current status and future dircotions. In T.S. Horn (idd.), Adrances in spont psychofogy (pp. 119-141). Champaign. IL: Human Kineties.

Gould, D., l'uffey. S., Hardy, L.. \& Loachbaum, M. (1993). Multidimensional state anxiety and nuiddle distance running performance: An exploratory examination of Hanin's (1980) zone of optimal functioning hypothesis. Journal of Applied Spont Psychology. 5, 85-95. 
Hanin, Y.L. (1978). A study of anxiely in sport. In W.P. Strath (Ed.), Spon Psychology: An analysis of ahletic behavior (p). 236-249). Ithaca, NY: Mouvement Publications.

Hanin, Y.L. (1986). State-trait anxiety research on sports in USSR. In C.D. Spielberger \& R. Díaz Guerero (Eds.). Cross-cultural anxiety (Vol. 3, pp. 45-64), Washington, DC: Hemisphere.

Hanin, Y.L. (1989). Interpersonal and intragroup anxiety in sports. In D. Hackfort \& C.D. Spielberger (Eds.), Anxicty in sport: An intemational perspective (pp. 19-28). New York: Hemisphere.

Hanin, Y.L. (1994a). Individual zone of optimal functioning (IZOF) model: An idiographic approach to pertomance anxicty. $\ln \mathrm{W}$. Stratub \& K. Henshen (Eds.), Sport psychology: An analysix of athlete's behavior ( $3^{\text {rd }}$ ed. pp. 250-292). Ithaca, NY: Mouvement Publications.

Hanin, Y.L. (1994b, April). Idiographic assessment of performance cmotions: A computerized program using the IZOI methodology. Procedings of the /st National Congress of Elite Finnish Couches (pp. 123-128). Jyväskyla, Finland.

Harger, G.J., \& Raglin, S.J. (1994). Correspondence between actual and recalled precompetition anxiety in collegiate track and field athietes. Jound of Spon \& Exercise Psychology, $16,206-211$

Imlay, G.S., Carda, R.D., Stanbrough, M.E.. Dreining, A.M., \& O'Connor. P.J. (1995). Anxiety and performance: A test of zone of optimal functioning theory. International Journal of Spont Psychology, 26. 295-306.

Jones, G., Hanton, S., \& Swain, A. (1994). Intensity and interpretation of anxiety symptoms in elite and non-elite spons performers. Personality and Individual Differences, 17. 657663.

Krane, V. (1993). A practical application of the anxjety-athletic performance relationship: The zone of optimal functioning hypothesis. The Sport Psychologist, 7, 113-126.

Landers, D.M. \& Boutcher. S.H. (1986). Arousal-performance relationship. [n J. Williams (Ed.). Applied spon psychology (pp. 163-183). Palo Alto, CA: Mayfield.

Martens, R., Burton. D., Vealcy, R.S., Bump, L.A., \& Smith, D. (1990), The development of the Competitive State Anxiety Inventory-2 (CSAI-2). In R. Martens, R.S. Vealey, \& D. Burton (Eds.), Competitive anxiety in spont (pp. 117-190). Champaign, IL: Human Kinetics.

Martens, R., Vealey, R.S.. \& Buton, D. (1990). Competitive anxiery in sport. Champaign, IL: Human Kinetjes.
Pons, D. (1994). Un cisudio sobre la relación entre ansiedady radimiento en jugadores de golf. Unpublished doctoral dissertation. Universidad de Valencia, Spain.

Raglin. J.S. (1992). Anxiety and sport performance, In J.O. Holloszy (Ed.), Exerise and sports sciences reviews (Vol. 20, pp. 243273). Baltimore. MD: Williams \& Wilkins.

Raglin, J.S.. \& Morgan, W.P. (1988). Predicted and actual precompetition anxicty in college swimmers. Journal of Swimming Rescard $h$, 4. 5-7.

Raglin. J.S. \& Morris. M.J. (1994). Precompetition anxicty in woman volleyball players: A test of $Z O F$ theory in a team sport. British Joumal of Sport Medicine 28, 47-51.

Raglin, J.S., \& Turner, P.E. (1992). Predicted. actial and optimal precompetition anxiely in adolescent track and field athletes. Sictindinatian Joumal of Medicine Scince Sports, 2, $148-152$.

Raglin, J.S.. \& Tumer. P.E. (1993). Anxiety and performance in track and field athletes: A comparison of the inverted-U hypothesis with zone of optimat functioning theory. Personality and Indinidual Differenes 4, 163-171.

Raglin, J.S.. Morgan, W.P., \& Wise, K.J. (1990). Pre-competition anxiety and performance in female high school swinmers: $\mathrm{A}$ lest of optimal functioning theory. International Joumal of Sport Medicine, 11, 171-175.

Roca, J., Pérez, G. \& Lázaro, i, (1991). Determinación del nivel óptimo de ansiedad en el alto rendimiento competitivo: contribución de los componentes somáticos y cognitivos. Revista de Mnestigacion y Doctamentacion sobre las Ciencias de la Ldracion Fisica y del Deporte, 7. $71-79$.

Spiciberger, C.D., Gorusch, R.L.. \& Lushene, R.E. (1970). Manual for the State-Trait Anxiety lnuentony. Palo Alto, CA: Consulting Psychologist Press. (Spanish translation: Spielberger, C.D., Gorusch, R.L., \& Lushene, R.E. (1988). Cuestionario de Ansiedad Estado-Rasgo (STAIJ. Madrid: TEA.)

Turner P.E., \& Raglin, J.S. (1996). Variability in precompetition anxiety and performance in college track and field athletes. Medicine and Scionce in Sport and Exertise, 28, 378-385.

Woodman, T., Albison, J.G., \& Hardy, L. (1997). An investigation of the zones of optimal functioning hypothesis within a multidimensional framework. Journal of Sport \& Exercise Psychology, 19.131-141.

Received July 9, 1999

Revision received June 8,2000 Accepted Jume 20, 2000 